\title{
Achieving More With Less: Extra Milers’ Behavioral Influences in Teams
}

\author{
Ning Li \\ The University of Iowa \\ ning-li-1@uiowa.edu \\ Helen Hailin Zhao \\ The University of Iowa \\ hailin-zhao@uiowa.edu \\ Sheryl Walter \\ The University of Iowa \\ sheryl-walter@uiowa.edu \\ Xin-an Zhang \\ Shanghai Jiaotong University \\ xinanzhang@sjtu.edu.cn \\ Jia Yu \\ The University of Iowa \\ jia-yu@uiowa.edu
}

Acknowledgments: The authors would like to acknowledge Mark Griffin, the Action Editor of our manuscript, as well as two anonymous reviewers, who provided invaluable assistance with the shaping of the ideas and writing contained herein. We also thank Brad Harris for generative feedback. This research was partially supported by the National Natural Science Foundation of China (grant no. 71302012 and 71472123).

Correspondence concerning this article should be addressed to Ning Li, Department of Management and Organizations, Tippie College of Business, The University of Iowa, E-mail: ning-li-1@uiowa.edu 


\title{
Achieving More With Less: Extra Milers’ Behavioral Influences in Teams
}

\author{
Abstract \\ Teams are composed of individual members who collectively contribute to team success. \\ As a result, contemporary team research tends to focus on how team overall properties (e.g., the \\ average of team personality and behavior) affect team processes and effectiveness, while \\ overlooking the potential unique influences of specific members on team outcomes. Drawing on \\ minority influence theory (Grant \& Patil, 2012), we extend previous teams research by \\ demonstrating that an "extra miler” (i.e., a team member exhibiting the highest frequency of \\ extra role behaviors in a team) can influence team processes and ultimately team effectiveness \\ beyond the influences of all the other members. Specifically, based on a field study, we report \\ that the extra miler's behavioral influences (i.e., helping and voice) on team monitoring and \\ backup processes and team effectiveness are contingent upon his or her network position in the \\ team, such that the member tends to have stronger influence on team outcomes when the member \\ is in a central position. We also find that even a single extra-miler in a vital position plays a more \\ important role in driving team processes and outcomes than all the other members do. Therefore, \\ our research offers an important contribution to the team literature by demonstrating the \\ disproportional influences of specific team members on team overall outcomes.
}

Key words: team process, social network, helping, voice, team effectiveness 


\section{Achieving More with Less: Extra Milers’ Behavioral Influences in Teams}

Contemporary organizations often rely on teams for making decisions, solving problems, and developing creative products and services. Conventional wisdom suggests that some teams perform better than others do because either they are composed of better members (e.g., members with desirable characteristics) or they have better team processes that motivate members to exhibit functional behaviors toward team goal accomplishment. A substantive portion of extant team research assumes that team performance is determined by the majority of team members and thus tends to adopt a simplified model that focuses on overall team properties (the “sum”) rather than individual characteristics (the “parts”) (Mathieu, Maynard, Rapp, \& Gilson, 2008). Consequently, both organizational scholars and practitioners often espouse that an effective way to increase team effectiveness is to improve the overall, collective characteristics and behaviors of the team.

Unfortunately, this heuristic perspective on team research is based on an oversimplified assumption that individuals within a team tend to be interchangeable and play an equal role in driving team success (i.e., isomorphism, Kozlowski \& Klein, 2000). Challenging this assumption, recent research has found that individual team members can display disproportional influences on team outcomes, such that certain members play more critical roles in determining team performance than others (Humphrey, Morgeson, \& Mannor, 2009). Relatedly, Grant and Patil (2012) proposed a theoretical model explicitly arguing that a few individuals can significantly change team helping norms through modeling (i.e., consistently displaying helping behavior towards other team members) and voice (i.e., speaking up and making constructive suggestions to change the status quo) behaviors. From a different lens, another recent study demonstrates the non-normal distribution of individuals' performance and suggests that, if "most performance 
outcomes are attributable to a small group of star performers, then both theory and practice must adjust to the substantial role played by these individuals” (O’Boyle \& Aguinis, 2012, p. 106). Thus, taken together, it is important to recognize that teams are composed of individuals with unique histories, knowledge, abilities, and performance potential who may disproportionally influence team dynamics and outcomes (i.e., discontinuity assumption, Kozlowski \& Klein, 2000).

Despite the aforementioned advancements, very few studies to date have empirically examined the disproportional influences of team members on team outcomes (Mathieu et al., 2008). As a result, at least two important questions remain unanswered: (1) Are levels of team success attributable to all members’ collective efforts or just a few special team members? And, if so, (2) how do these specific team members contribute to levels of team success? Addressing these questions, we draw on Grant and Patil's (2012) theory on minority influence to explore how a single team member that exhibits a high frequency of extra role behaviors (i.e., helping and voice) affects key team processes and team effectiveness above and beyond the influences of all other team members. Drawing from the common axiom that some employees are willing to go "the extra mile", we refer to these select team members as "extra milers" (operationalized in the present study as individuals with the highest frequency of helping [i.e., the maximum helping member] or voice [i.e., the maximum voice member] behaviors as rated by their peers).

We then examine how extra milers' extra-role behaviors diffuse within the team to affect overall team processes and outcomes. Integrating minority influence research (Grant \& Patil, 2012) and social network theory (Kilduff \& Brass, 2010), we posit that extra milers’ behavioral influences are contingent upon his or her unique network position in the team. Specifically, we 
argue that the extra miler tends to affect the team to a greater extent when he or she is well connected with other members (i.e. occupying a central workflow position).

The present study makes several theoretical contributions to the literature. First, we add to a scant, yet impactful line of scholarship that compliments the traditional view of teams research that the majority of team members are the primary driving force of team success. Some notable studies (e.g., Barrick, Stewart, Neubert, \& Mount, 1998; LePine, Hollenbeck, Ilgen, \& Hedlund, 1997; Neuman \& Wright, 1999) have preliminarily advanced this rationale by examining the effects of team maximum/minimum values (e.g., rating scores) of given characteristics on team performance. However, most of these studies fall short of directly accounting for the characteristics of the team member responsible for these maximum/minimum scores. Remedying this concern, we make the case that the actual influence of these maximum/minimum scores is determined by the structural characteristics of the person who carries these scores. We use the maximum value of extra-role behavior to identify an extra-miler in each team, and then study how this individual's network position interacts with his/her behaviors in explaining proximal and distal team outcomes. Although our model primarily focuses on the influence of team members' desirable work behaviors, its underpinnings may also inform the destructive effects of a single member's undesirable work behaviors (cf. how a bad apple can spoil the whole barrel).

Second, we elucidate the joint influence of the extra miler's behavioral profile and his or her network position on team processes and team effectiveness. Though previous research has separately supported the importance of team member behaviors (e.g., Marks \& Panzer, 2004; Van Der Vegt, Bunderson, \& Oosterhof, 2006) and team member positions (e.g., Sparrowe, Liden, Wayne, \& Kraimer, 2001; Venkataramani \& Tangirala, 2010) on overall team processes 
and outcomes, little is known regarding how central/peripheral network positions debilitate or magnify the influences of member behaviors. Drawing from social network theory, which argues that individuals develop varying levels of reputations, status, and power through social relationships with others (Borgatti, Mehra, Brass, \& Labianca, 2009), we contend that the impact of an extra miler on team processes and team effectiveness is contingent upon the centrality of network position. In doing so, our paper sheds light on the heretofore-unexplored role of disproportional member influences.

Third, our study contributes to the social network literature by examining the bottom-up influence of a specific member on overall team performance. This is important as previous social network studies have generally related individual network position to individual outcomes and examined how team network structure influences team outcomes without empirically acknowledging that individual factors might influence team outcomes (Brass, Galaskiewicz, Greve, \& Tsai, 2004). For instance, some studies have found that overall attributes of the network (e.g., network density, centralization) are positively related to team outcomes (Balkundi \& Harrison, 2006; Sparrowe et al., 2001), whereas others have found that attributes of an individual's network (e.g., actor centrality) are positively related to individual outcomes (e.g. Scott \& Judge, 2009; Sparrowe et al., 2001; Sparrowe \& Liden, 2005; Venkataramani \& Tangirala, 2010). In contrast, our study is one of the first to employ a cross-level lens that examines how the behaviors of a critical member disperse across the whole team.

Finally, our work yields an empirical test of several key ideas proposed in Grant and Patil's (2012) theoretical framework and, in doing so, extends their model by including team effectiveness criteria such as team performance and creativity. This is an important extension, as many modern organizational contexts expect teams to perform reliably and generate creative 
business solutions (Madjar, Greenberg, \& Chen, 2011; Van de Ven \& Johnson, 2006). Further, diverging from previous research that treats helping and voice as end results (McClean, Burris, \& Detert, 2013), our study investigates how extra milers’ helping and voice behaviors predict specific team mechanisms and outcomes. In sum, we answer important questions of how, when and why an extra miler contributes to team performance and creativity through his or her extrarole behaviors. The overall theoretical model is presented in Figure 1.

Insert Figure 1 about here

\section{Theoretical Development}

According to minority influence theory (Grant \& Patil, 2012), helping and voice are two theoretical paths through which an individual can proactively influence their work unit. The central message of the theory is that one or a few specific members' helping and voice behaviors can destabilize the team norm of just focusing on self-interest and eventually shift it to the team norm of helping one another. In line with this model, as well as other traditional extra-role perspectives (i.e., the affiliative-challenging framework of extra-role behaviors; Brief \& Motowildo, 1986; Organ, 1988; Van Dyne, Cummings, \& Parks, 1995), we focus herein on helping and voice as two major forms of extra milers’ behavioral influence.

Helping is a typical affiliative extra-role behavior that builds and maintains harmonious interpersonal relationships and facilitates team cooperation by providing resources and efforts to others in need (George \& Brief, 1992; Van Dyne \& LePine, 1998). Voice, on the other hand, is a challenging extra-role behavior through which individuals attempt to improve the current status quo by identifying problems and providing suggestions (LePine \& Van Dyne, 1998; Van Dyne \& LePine, 1998). Although helping and voice represent different aspects of extra-role behaviors, they are both functional behaviors that promote collective welfare. Further, in comparison to in- 
role behaviors, helping and voice are less mandated by formal job descriptions and expectations (Van Dyne et al., 1995) and thus are more likely to be spread across the team at one's discretion. In the present study, we examine how extra milers influence team processes and ultimately effectiveness. We operationalize an extra miler as the individual team member that demonstrates the highest frequency of helping or voice behaviors based on ratings from each of his peers/fellow team members. This operationalize is appropriate given our theoretical lens, as it reflects the behavioral consistency that is likely required for changing team norms (Bandura, 1977; Cialdini \& Goldstein, 2004; Grant \& Patil, 2012). Likewise, our focus on a single extramiler provides an ideal opportunity to uncover the specific mechanisms by which one member can influence overall team outcomes. It is important to note that within any given team the maximum helping member may or may not be the same person as the maximum voice member, as these behaviors are likely driven by different interpersonal and/or dispositional motives (Chiaburu, Oh, Berry, Li, \& Gardner, 2011). For example, LePine and Van Dyne (2001) found that people with high agreeableness tend to engage in helping, but not in voice. As a result, we do not combine helping and voice, but instead advance a more precise model of the behavioral influence of both types of extra milers.

Our model links an extra miler’s helping or voice behaviors to team processes. Team processes refer to the behavioral standard socially enforced by team members over time to exchange materials and information within a team (Marks, Mathieu, \& Zaccaro, 2001). Team processes capture the collective interdependent actions as a result of coordination among all members, which is conceptually different from individual team member's independent actions (Li, Kirkman, \& Porter, 2014). For example, a behavior whereby an individual independently helps another teammate is conceptually different from an interdependent action in which 
multiple members collectively share the workload and backup one another. Therefore, individuals can behave in line with a team process and gain social approval; violate a team process and receive social disapproval; challenge the existing process and eventually change it; or initiate a new process and help reinforce and sustain it over time (Bettenhausen \& Murnighan, 1985; Cialdini \& Goldstein, 2004; Grant \& Patil, 2012; Li et al., 2014; Wood, Lundgren, Ouellette, Busceme, \& Blackstone, 1994).

Although research has identified a number of different types of team processes, we focus on one of the most critical and theoretically relevant processes to guide our rationale: team monitoring and backup. Team monitoring and backup is defined as "assisting team members to perform their tasks, which may occur by (1) providing a teammate verbal feedback or coaching, (2) assisting a teammate behaviorally in carrying out actions, or (3) assuming and completing a task for a teammate” (Marks et al., 2001, p. 363). The monitoring and backup process is essential to team overall effectiveness because, by definition, working in a team requires at least a minimum level of cooperation, monitoring, and control among multiple team members, each of whom has unique characteristics, to strive toward common goals and conform to certain behavioral standards (Li et al., 2014; Ouchi, 1979). Moreover, according to Grant and Patil’s (2012) theory of minority influence, the team monitoring and backup process is likely influenced by members' helping and voice behaviors because it contains two aspects of team helping norms: a) how team members develop standards for acceptable behavior and performance (e.g., norms) and b) how team members assist one another (e.g., helping).

Isomorphic views of team dynamics might suggest that helping or voice by one person will always have an unconditional impact on team processes. Yet in a real team setting, which is characterized by more complex interaction patterns (Mathieu et al., 2008), some members are 
clearly more influential than others and thus will have a disproportional impact compared to others enacting the same behaviors (Humphrey et al., 2009). One conceptualization that might explain this disproportionate impact is members' central vs. peripheral status in their team’s workflow network (i.e., the flow of inputs/outputs and the interdependence among different team members; Brass, 1984). In essence, we argue that the presence/absence of a tie in workflow network can either amplify or diminish team members’ behavioral influence. Figure 2 graphically depicts examples of two different network structures. Within these networks, each node (star or circle) represents a team member (with the star representing the extra miler and the circles represent team members other than the extra miler) and a line between two nodes represents a work relationship between two team members. In Figure 2a, the extra miler occupies a central position in the workflow network because he or she has a high accessibility to the rest of the team. Since the extra miler is well connected, his or her behaviors can easily diffuse across the team. However, in Figure 2b, the extra miler occupies a peripheral position in the workflow network so it is more difficult for him or her to influence the rest of the team.

\section{Insert Figure 2 about here}

Based on the logic above, we argue that the behavioral influence of an extra miler is contingent upon his or her network centrality. In doing so, we are able to separate the influence of a personal attribute (e.g., behavioral profile) from a network-based attribute (e.g., network position). It is worth noting that being an extra miler does not necessarily mean occupying a central position because network centrality describes the structure of social ties in a particular network while being an extra miler captures high frequency on a behavioral criterion. Indeed, empirical findings have found only modest correlations between network-based attributes and personal attributes (e.g., Klein, Saltz, \& Mayer, 2004), suggesting the two constructs are largely 
independent from one another. In summary, an extra miler in a central position may display powerful influences on team outcomes that are beyond the influence of all the other teammates.

\section{Hypotheses}

Helping is considered a desirable type of extra-role behavior at work, with a substantive body of research supporting its virtues. For instance, helping can improve team cohesiveness (Anderson \& Williams, 1996; Dukerich, Golden, \& Shortell, 2002), strengthen emotional bonds among team members (Dutton, Worline, Frost, \& Lilius, 2006; Kahn, 1998) and enhance overall team effectiveness (George \& Bettenhausen, 1990). Similarly, voice is also a desirable workplace behavior because it aids in early problem/opportunity identification, instigates functional changes, and insulates against unexpected situations (Tangirala \& Ramanujam, 2008; Weick \& Sutcliffe, 2001). Despite the recognized importance of both types of extra-role behaviors, little is known regarding if, or how, team members’ efforts differentially influence team processes.

We propose there are two important factors to make such influence successful: the frequency of helping and voice behaviors, and the network centrality of the source of these behaviors. First, we focus on the extra miler's behavioral influence to uncover the relationship between "part” (i.e., individual behaviors) and "whole” (i.e., team processes and effectiveness) in team dynamics. Theory of minority influence highlights the importance of the frequency and consistency of a single member’s behaviors in the influence process (Grant \& Patil, 2012). Social learning theory also suggests that attention is the first step of social learning and repeated patterns of behaviors are more likely to draw others’ attention (Bandura, 1977). Broadly speaking, helping and voice both signal the appropriateness of going beyond one’s own delineated tasks for the good of the team (Schultz, Nolan, Cialdini, Goldstein, \& Griskevicius, 
2007). A high quality team monitoring and backup process involves both monitoring and backup. The monitoring aspect of the process is about developing acceptable behavioral standards and detecting deviations from this standard. The backup aspect, on the other hand, refers to engaging in cooperative behaviors, such as picking up slack, fixing errors and supporting each other (Marks \& Panzer, 2004; Porter, Hollenbeck, Ilgen, Ellis, West, \& Moon, 2003).

Voice and helping functionally relate to these two different aspects and, therefore, are both relevant to predicting team monitoring and backup processes. In addition to the inherent links between extra role behaviors and team monitoring and back, theory of minority influence (Grant \& Patil, 2012) suggests that consistently displaying helping behavior sends a clear message to the appropriateness of helping each other (i.e., backing up). As a result, members tend to reflect upon their current processes and reciprocate the helping they received from the extra miler. As a result, team overall process is likely improved. Similarly, repeatedly voicing the need of change destabilizes existing norms and pushes team members to asking questions regarding the current process. Therefore, all the members tend to keep a close eye on the ongoing team process. Essentially, these two types of behaviors positively influence the whole team's problem identification process (e.g., watching out for unbalanced workload) and problem solving process (e.g., helping each other to achieve the common goal).

The second important consideration is whether the repeated behavioral pattern of helping or voice is influential or not. Grant and Patil's (2012) theory suggests that the more influential the individual, the better the chance to change team processes. Similarly, the theory of strategic core proposed by Humphrey et al. (2009) finds that a person's influence on team performance is largely constrained by the position (core vs. non-core) he or she holds. Consistent with these theoretical perspectives, we propose that the extra miler's behavioral influence is dependent on 
his or her accessibility to other members in the workflow network (i.e. network centrality). Workflow network describes the extent of team members' dependence on a position holder for work-related input (Brass, 1984). A central position in the workflow network indicates that the member is well-connected to the rest of the team in work-related interactions (Kilduff \& Brass, 2010). We believe that workflow network centrality is an appropriate way to capture the level of a team member's influence magnitude, because it is less biased than a self-reported influence measure or researcher-determined position importance, and it reflects both formally prescribed and informally emerged work relationships. As a result, the extra miler's behavioral influences on team processes is likely to be amplified by the member's central position in the team due to the effects of social proximity (Marsden \& Friedkin, 1993; Zohar \& Tenne-Gazit, 2008).

In other words, a central extra miler often determines the quality of team monitoring and backup process for the team. To better illustrate how an extra miler influences team processes, we present hypothesized interactions between the extra miler’s behavioral influence and centrality on team processes in Figure 3. We expect that central extra milers are more likely to influence team monitoring and backup processes than peripheral extra milers. More specifically, the high condition of workflow centrality has a steeper slope than the low condition, because central members are able to change the team processes but peripheral members are not as influential. There is a process gain when the extra miler has high helping (or voice) and occupies central position and a process loss when the extra miler has low helping (or voice) and occupies central position. In peripheral position, an extra miler is unlikely to change the team process regardless of the level of helping (or voice). Thus, we predict:

Hypothesis 1 . The maximum helping member is more likely to influence team monitoring and backup processes if he or she occupies a central position in the workflow network. 
Hypothesis 2. The maximum voice member is more likely to influence team monitoring and backup processes if he or she occupies a central position in the workflow network.

Insert Figure 3 about here

We have discussed that how the maximum helping member and maximum voice member influence team processes when he or she occupies central network positions in the workflow network. Next, we propose that the positive changes in team processes brought about by the extra miler can enhance two important team outcomes: team performance and creativity. Specifically, team performance is often a product of team members’ interdependent efforts (Mathieu et al., 2008). However, a team may fail to reach their optimal performance because some incompetent members are struggling to keep the pace of the team or the team has suboptimal distributions of workload impeding team members’ full potential (Porter et al., 2003). As a result, monitoring and backup behaviors among members, such as assisting less competent teammates and rebalancing of the workload, become a key factor improving team performance (Li et al., 2014).

We further argue that the maximum helping member tends to indirectly impact team performance via team monitoring and backup process. The mediating mechanism of team processes has been widely demonstrated in studies on Input-Process-Output models (e.g., Campion, Medsker, \& Higgs, 1993; Mathieu, Heffner, Goodwin, Salas, \& Cannon-Bowers, 2000). The monitoring and backup process is a collective phenomenon that develops over time from individual members' understandings of each other’s job, willingness to seek and provide help, and adjustment among underutilized members (Porter et al., 2003). It facilitates task 
completion as a team, acknowledges and addresses mistakes that may jeopardize team success, and helps team members develop job-related skills. As a result, team performance is improved. On the other hand, if the extra miler occupies a peripheral position in the workflow network, it is difficult for him or her to generate a great enough impact to change the shared monitoring and backup process. Without a mutually agreed monitoring and backup process, many of these spontaneous coordination efforts will not occur, and team performance will consequently be delayed or hindered (Barrick et al., 1998; Dickinson \& McIntyre, 1997).

In addition to team performance, we also examine team creativity as the other important team outcome. According to the multilevel theory of creativity (Drazin, Glynn \& Kazanjian, 1999; Woodman, Sawyer \& Griffin, 1993), team creativity is not a simple average of team members’ creative behaviors, but a negotiated product among multiple members through complex social and contextual mechanisms. We believe that if the maximum voice member also occupies central position in social network, he or she is more likely to influence team monitoring and backup and subsequent team creativity. Specifically, employee voice is change-oriented and aims to improve the status quo by providing suggestions and identifying problems. Because of the change-oriented nature, voice is often considered as an initial step for generating creative ideas. For example, Zhou and George (2001) argue that creativity is an expression of voice. Similarly, a study conducted by Kay (1989) suggests that typical voice behaviors (e.g., “proposing new ways of doing things” and “making suggestions on how to improve things”) are consistent with the definition of creativity (Zhou \& George, 2001). Therefore, consistent voice behaviors are important sources for teams generating novel ideas, particularly if the maximum voice member occupies a central position in workflow network that tends to accelerate the diffusion of new ideas. 
Team creativity emphasizes that teams are hotbeds of creativity because team members are able to draw from one another's resources, expertise and experiences to generate new ideas (Bain, Mann, \& Pirola-merlo, 2001). However, team creativity research suggests that team members are unlikely to propose novel ideas if they expect their ideas to be dismissed or criticized by other team members (Amabile \& Gryskiewicz, 1987; West \& Anderson, 1996), which highlights that team processes play an important role in facilitating team creativity. In order to facilitate team creativity, it is important to have a supportive team process, such as monitoring and backup, that allows team members to closely interact and openly communicate with one another. Zhou and George (2001) tested this rationale at the individual level and found that coworkers' useful feedback, helping, and support were helpful for creativity and innovation. At the team level, when members actively provide feedback, help one another, and optimize team workload, they are more likely to collaborate, share, and bounce ideas off each other to generate novel solutions. Thus, we propose that the maximum voice member has an indirect effect on team creativity through the process of monitoring and backup. This mechanism is stronger when the voice member is more prominent in workflow network.

Hypothesis 3. The interactive effect of the maximum helping member's behavior and centrality in the workflow network influences team performance through team monitoring and backup processes, such that the helping member tends to have a stronger indirect effect on team performance when he or she is in a central position rather than in a peripheral position.

Hypothesis 4. The interactive effect of the maximum voice member's behavior and centrality in the workflow network influences team creativity through team monitoring and backup processes, such that the voice member tends to have a stronger indirect effect 
on team creativity when he or she is in a central position rather than in a peripheral position.

\section{Method}

\section{Sample and Data Collection}

We collected data from manufacturing teams working for a large petrochemical company in China as a part of a broader data collection effort. The company’s product lines include: refined oil products, petrochemicals, synthetic resins, and synthetic fiber polymers. Each product line performed its own planning, managing and manufacturing functions. The company used work teams to accomplish various functional responsibilities.

We invited 104 teams to participate in the study. Team supervisors were first asked to complete a supervisor survey. Next, supervisors distributed the employee survey to their 837 respective team members. In an effort to protect against undue bias, employees returned the surveys in sealed envelopes directly to research assistants. We sought to encourage employee participation by offering a gift valued at approximately five dollars to all survey respondents. We obtained responses from all 104 supervisors and 739 team members (for a response rate of 88.3\%). The average team size was 7.2 (range of two to 19 members). We eliminated teams with only two members as well as those with less than an $80 \%$ team response rate for our analysis. This resulted in a final sample of 87 teams (Individual $N=659$ members).

\section{Measures}

Team members evaluated their team's monitoring and backup process, social network structure (i.e., workflow centrality [how often the rater relied on each co-worker for work related inputs]), and the helping and voice behaviors for each member of their team. To facilitate accurate and complete responses, each team member's survey contained a list of all members’ 
names (provided by the company’s human resources department). Team supervisors rated the team's performance and creativity. With the exception of the team performance and social network questions, all study items used a seven-point Likert-type scale (ranging from 1 = "strongly disagree" to 7 = "strongly agree"). The surveys were translated from English to Chinese and back to English following the standard translation and back-translation procedures (Brislin, 1986).

Team monitoring and backup. Members rated their team's monitoring and backup processes using three items from the team process scale developed by Mathieu and Marks (2006), which is based on the conceptualization of Marks et al. (2001) and used in recent team studies (Kukenberger, Mathieu, \& Ruddy, 2012). The three items are: "In this team we actively work to develop standards for acceptable team member performance", "In this team we actively work to balance the workload among our team members", and "In this team we actively work to assist each other when help is needed.” Cronbach’s alpha was .81. Team members' responses were aggregated at the team level. To determine whether aggregation was appropriate, we calculated intra-class correlation coefficients (ICC (1) and ICC (2)). ICC (1) indicates the proportion of variance in ratings due to team membership, whereas ICC (2) indicates the reliability of team mean differences (Bliese, 2000). We also tested whether average scores differed significantly across teams (indicated by an $F$ test from a one-way analysis of variance [ANOVA] contrasting team means on each variable). ICC (1), ICC (2), and respective $F$-values were .13, .52, and $F$ (87, $564)=2.07, p<.01$. While we note that this ICC(2) value of .52 is lower than the .70 value that is sometimes recommended for aggregation, the ICC(2) value is dependent on the ICC(1) value and the group size (Bliese, 1998). Our ICC(2) value is compatible to previously reported values 
in studies with the similar group size (Brown \& Trevino, 2006; Hofmann \& Jones, 2005; Ilies, Wagner, \& Morgeson, 2007; Zhang, Hempel, Han, \& Tjosvold, 2007).

Helping. Individuals’ helping behavior was measured using two items from Farh, Zhong, and Organ’s OCB scale (2004). Farh, Hackett, and Liang (2007) shortened the original scale to a 3-item helping/altruism scale, which is intended to capture work related helping behavior in the workplace. This three-item scale included a measure "Helps new employees adapt to their workload”, which was not used in this study because new members rarely joined the teams (fewer than 6\% employees were newcomers). Therefore, team members were asked to rate the helping behavior of each of their coworkers based on the two following characteristics: "initiate help to co-workers who have heavy workload” and "willing to help co-workers solve workrelated problems”. Cronbach’s alpha was .93. Because multiple coworkers rated the focal team member's helping behavior, we further calculated ICCs to assess inter-rater reliability. Specifically, ICC (1) and ICC (2) were .22 and .70. For the purpose of testing our hypotheses, the score of the individual with the maximum co-worker rated helping behavior was selected as the helping extra miler.

Voice. Individuals’ voice behavior was measured using two items from the PRC OCB scale developed by Farh et al. (2004). Farh et al. (2007) used these two items to represent employee voice behavior. Team members were asked to rate the voice behavior of each of their coworkers based on the following two characteristics: "raise suggestions to improve procedures of one’s job” and "bring forward suggestions that contribute to the development of the unit”. Cronbach’s alpha was .92. Similarly, ICC (1) and ICC (2) were .26 and .74. Again to test our hypotheses, the member with highest voice rating in a team was chosen as the voice extra miler within the team. 
Team performance. Team performance was rated by the team supervisor using an 8-item scale developed by Barrick et al. (1998), which was used in manufacturing teams. The items were rated using a 7-point scale $(1=$ somewhat below requirements, 7 = consistently exceeds requirements). Rated items included aspects that tap team routine tasks, such as planning and allocation, knowledge of tasks, quality of work, quantity of work, commitment to the team and overall job performance. Cronbach’s alpha was .92.

Team creativity. Team creativity was rated by the team supervisor using a 5-item modified version of Zhou and George’s (2001) creativity scale. Items were rated using a 7-point Likert-type scale (1=strongly disagree, 7=strongly agree). Sample questions included “in my team, team members come up with new and practical ideas to improve performance” and "in my team, team members often have a fresh approach to problems”. Cronbach’s alpha was .91.

Network centrality measures. We used a social network approach to evaluate the workflow centrality of the team members. Team members were provided a list including all their teammates and asked to rate each of their team members’ workflow by answering the following question about each team member: "To what degree do you rely on this person to provide you with inputs to your job?”. Team members used a 5-point frequency scale $(1=$ not at all, $5=$ very much) to rate these measures.

Normed in-degree workflow centrality scores were computed for each member using UCINET 6 for Windows (Borgatti, Everett, \& Freeman, 2002). In-degree centrality measures centrality based on the individual being reported as focal by another team member. Normed centrality scores were used to adjust the members' centrality scored for team size thereby allowing the comparison of centrality scores across teams of varying sizes. Higher normed indegree centrality scores represent that a person has a more central position within the team. As 
such, an individual with a higher normed in-degree workflow centrality provides more work inputs to other members of his team. The range of the network centrality for the maximum helping individuals is: 37.5 - 100. The range of the network centrality scores for the maximum voice individual is: $45.0-100$.

Control Variables. Because team size may affect team processes, we controlled for team size. A set of control variables were also included so that we could analyze the impact the extra miler’s influence and network position beyond the average team influence and team network effects.

In order to assess the relationship between the extra miler's behaviors (beyond the team's average behaviors) and team outcomes, we controlled for the mean of the team score (except the extra miler's behavior score) and the standard deviation of the team score on the behavior of interest. For example, when analyzing the relationship between the maximum voice member’s behavior and the team monitoring and backup process we calculated the mean voice behavior score for everyone on the team with the exception of the maximum voice member and used the team mean voice score as a control. It is also likely that there is variability in the dispersion of voice behaviors across teams. For example, some teams may have low variability with all of the members exhibiting approximately the same level of voice behaviors and other teams may have higher variability with largely different scores among members. The amount of variability in voice behaviors may influence team processes, so we also controlled for the standard deviation of the voice behavior across teams. Similarly, when analyzing the relationship between helping and team monitoring and backup we controlled for the mean team helping score (minus the maximum helping member's behavior) and the standard deviation of helping behavior. 
Because both the centralization and the density of the networks may influence processes, we also controlled for these network characteristics in our analysis (Sparrowe et al., 2001). Centralization indicates whether a network is centralized around a small number of members within the team (Kilduff \& Brass, 2010). Network density is assessed by dividing the actual number of social ties in the network by the maximum number of ties possible (Kilduff \& Brass, 2010) and represents the cohesiveness of the network.

\section{Results}

\section{Descriptive Results}

Table 1 presents means, standard deviations, and intercorrelations for the variables used in the study. As mentioned above the maximum helping member may not be the same person of maximum voice member, we thus created two separate datasets including the individual with maximum helping and maximum voice, respectively ${ }^{1}$. In our sample sixty of the 87 teams (69\% of the teams) reported the same person as the maximum helping member and voice member.

Insert Table 1 about here

\section{Confirmatory Factor Analyses}

We first conducted a series of confirmatory factor analyses (CFAs) using LISREL 8.8 (Jöreskog \& Sörbom, 1993) to evaluate the measurement model that was used and compare

\footnotetext{
${ }^{1}$ We created the dataset used for the helping analysis by first identifying the individual on each team with the highest mean co-worker rated helping behavior score (the maximum helping member). If more than one member on the team had an equally high helping score then one of these members was randomly chosen (a subsequent analysis using the non-selected high scoring individuals did not significantly change the results). We used the workflow centrality score for this maximum helper along with the team mean score for backup process and the supervisor rated task performance measures in the analysis. We used a similar process to create the dataset for the voice analysis (selecting the team member with the highest co-worker rated voice score and using that individual's workflow centrality in the analysis).
} 
competing measurement models. The results of the CFA analysis are presented in Table 2.

Because of the small sample size resulting from focusing on the team level, we created three parcels for the team performance and team creativity constructs. The hypothesized measurement model was a five factor model with the following constructs: voice behavior, helping behavior, team backup processes, team performance, and team creativity. This model displayed acceptable fit, $\chi^{2}(55)=66.68, p<.01$; comparative fit index $(\mathrm{CFI})=.99$, root-mean-square error of approximation $($ RMSEA $)=.05$, standardized root-mean residual $(\mathrm{SRMR})=.05$. Chi-squared difference tests confirmed that the proposed model fit better than the three alternative models that were tested. The first alternative model was a four factor model where the voice and helping behavior indicators were assumed to load on the same higher order factor (contextual behaviors), $\Delta \chi^{2}(4)=19.82, p<.01 ; \mathrm{CFI}=.97, \mathrm{RMSEA}=.07, \mathrm{SRMR}=.05$. The second alternative model was also a four factor model, but in this model the team performance and team creativity outcomes were modeled as a single performance outcome $\Delta \chi^{2}(4)=136.19, p<.01$; CFI $=.86$, RMSEA $=.17$, SRMR $=.09$. The final model was a three factor model where contextual behaviors, team backup process, and outcomes were each considered to be latent factors $\Delta \chi^{2}(7)$ $=155.74, p<.01 ; \mathrm{CFI}=.84, \mathrm{RMSEA}=.17, \mathrm{SRMR}=.10 .^{2}$

Insert Table 2 about here

\section{Tests of Moderation}

Hypotheses 1 and 2 were tested using hierarchical ordinary least squares (OLS) regression. We first present a baseline model (Model 1) and then create three additional models

\footnotetext{
${ }^{2}$ Because we focus on examining the discriminant validity at the construct level, we used helping and voice items from all team members' responses in CFAs. The results remain unchanged if we use helping and voice items from individuals with maximum helping and voice.
} 
for comparison purposes. We created the baseline model by entering the extra miler's behavior and network position score, as well as the following controls: team size, centralization and density of networks, and team dispersion of the predictor behavior. The second model adds the average team helping or voice behavior score of the remainder of team (everyone except the extra miler). Comparing Model 2 to Model 1 shows the incremental validity of including the behaviors of the remainder of the team beyond that of the extra miler. We then created the third model, which adds the interaction of the extra miler’s helping/voice behavior and that individual's workflow centrality. Comparing Model 3 to Model 2 indicates the incremental validity of having the extra miler in the central position beyond that of the remaining team members' behaviors. We then created a fourth model which removed the helping scores of the team. Comparing Model 4 to Model 3 indicates the amount of variance in team monitoring and backup impacted by removing the average team helping/voice score.

Table 3 reports the results for helping behaviors on team monitoring and backup (Hypothesis 1). Model 1 includes the main effects of the maximum helping member's behavior and his/her workflow centrality as well as the following controls: team size, workflow centralization, workflow density, and helping dispersion. These terms account for approximately $19 \%$ of the variance in team monitoring and backup. The addition of the helping score of the remainder of the team (Model 2) did not account for a significant amount of additional variance in the team's monitoring and backup process $\left(\Delta R^{2}=.01, p>.05\right)$. The interaction of helping behaviors and workflow centrality (Model 3) was significant $(\beta=.22, p<.05)$ and explained an additional $7 \%$ of variance in team monitoring and backup processes $(\Delta F[1,78]=7.70, p<.05)$. Thus, workflow centrality significantly moderated the relationship between helping behavior and team monitoring and backup. Results from Model 4 reveal that removing the average helping 
score of the remainder of the team did not significantly influence the amount of variance in team monitoring and backup that was accounted for $(\Delta F[1,79]=.85, p>.05)$.

Because removing the remaining team members’ mean score did not influence the variance and in an attempt to limit the use of unnecessary controls, Model 3 was used to test further moderated mediations. The results of the moderation analysis are presented in Figure $4 \mathrm{a}^{3}$, which depicts the interaction of helping behaviors and workflow centrality at one standard deviation above and below the mean. Simple slope analysis indicates that when the maximum helping member was in a central rather than a peripheral position, his or her helping behavior was more strongly related to team monitoring and backup process $(\beta=.35, p<.01$ vs. $\beta=-.05$, ns). These results support Hypothesis 1.

Insert Table 3 and Figure 4a about here

Table 4 reports the results for voice behaviors on team monitoring and backup (Hypothesis 2). The main effects of the maximum voice member's behavior and his/her workflow centrality as well as the control variables (Model 1) account for approximately 29\% of the variance in team monitoring and backup processes. Adding the average voice behavior score of the team (Model 2) does not account for a significant amount of additional variance $\left(\Delta R^{2}=.02\right.$, $p>.05$ ). The interaction of voice behaviors and workflow centrality (Model 3) was significant ( $\beta$ $=.14, p<.05$ ) and accounted for an additional $7 \%$ of variance beyond the main effects of voice

\footnotetext{
${ }^{3}$ When testing our model, we included several controls to check the robustness of our results. Although including the controls did not influence the significance of the interaction term, the control variables did impact the coefficients of first other predictors (i.e., centrality and behavior), which shifted the shape of the interaction because of multicollinearity. For example, in the presence of team meaning helping, the coefficient of maximum helping became negative. As a result, the multicolinearity effect could influence the accurate interpretation of the moderating effects. Therefore, we plotted the interactions without controls in both Figures 4a and 4b.
} 
and workflow centrality and controls presented in Model $2(\Delta F[1,78]=8.11, p<.05)$. Once again, removing the average voice behavior score of the remainder of the team (Model 4) did not significantly influence the variance in team monitoring and backup processes $(\Delta F[1,79]=1.28$, $p>$.05). Simple slope analysis (based on Model 3) suggests that when the maximum voice member was in a central rather than a peripheral position, his or her voice behavior was more strongly related to team monitoring and backup process $(\beta=.43 p<.01$ vs. $\beta=.12$, ns, Figure 4b). These results support Hypothesis 2.

Insert Table 4 and Figure 4b about here

\section{Tests of Moderated Mediation}

To test Hypotheses 3 and 4 we used an SPSS macro (PROCESS) designed by Hayes (2013). The PROCESS macro allows testing moderated mediation models to explore the conditional indirect effects as recommended by Edwards and Lambert (2007). The PROCESS macro also uses bootstrapping to estimate the indirect effects, which is preferred to the Sobel test (Baron \& Kenny, 1986) because bootstrapping overcomes the problem of non-normality violations (Hayes, 2009; Preacher \& Hayes, 2008).

Table 5 reports the results for Hypothesis 3. Results from the bootstrapped data show that at one standard deviation above the mean on our moderator variable (workflow centrality) the conditional indirect effect is significant $(\beta=.16)$ and 95\% confidence interval does not include zero (95\% CI [.03, .33]). In contrast, at one standard deviation below the mean the conditional indirect effect is small $(\beta=.01)$ and the confidence interval does contain zero (95\% CI [$.07, .11])$. Therefore, in support of Hypothesis 3 , the team monitoring and backup process 
mediated the impact of helping behavior on team performance when the individual had high workflow centrality.

Table 6 reports the results for Hypothesis 4. The bootstrapped data show that at high levels of workflow centrality the conditional indirect effect is non-significant as the 95\% confidence interval contains zero (95\% CI [-.07, .27]). Similarly, at low levels of workflow centrality the conditional indirect effect is also not significant (95\% CI [ -.02, .14]). Therefore, Hypothesis 4 is not supported.

Insert Tables 5 and 6 about here

\section{Additional Analyses}

We also examined the spillover effects of the maximum voice member's behavior on team performance and the maximum helping member's behavior on creativity by running two additional models. First, we examined whether the interactive effect of the voice member's behavior and workflow centrality influenced team performance through team monitoring and backup. We again used the PROCESS macro to test the spillover model. The conditional indirect effects were consistently non-significant at low levels of workflow centrality $(\beta=.02,95 \%$ CI [$.02, .14)$ and at high levels of workflow centrality $(\beta=.07,95 \%$ CI $[-.07, .27])$, suggesting that voice did not indirectly related to team performance. Second, we examined whether the interactive effect of the maximum helping member’s behavior and workflow centrality influenced creativity through team monitoring and backup. The conditional indirect effects were non-significant at low levels of workflow centrality $(\beta=.01,95 \%$ CI $[-.06, .08])$ but significant at high levels of workflow centrality $(\beta=.11,95 \%$ CI $[.07, .27])$. The results indicate an 
unexpected spillover effect of the maximum helping member on team creativity through the team monitoring and backup process, but only when the member occupies a central workflow position.

\section{Discussion}

Building upon minority influence theory (Grant \& Patil, 2012) and social network research, we extended the traditional focus on the effectiveness of the "whole" team properties to a focus on an extra miler's influence (e.g., a "part” of the team) on team overall outcomes. We argued that the extra miler contributes to a larger proportion of team effectiveness than does the rest of the team. We posited that team members’ personal attributes (e.g., behaviors) and network-based characteristics (e.g., centrality) are both important determinants of their influences in the team. Specifically, we supported a moderated mediation model, in which the extra miler's helping and voice behaviors and his or her position in the team (i.e. workflow network centrality) jointly influence the team monitoring and backup process, ultimately positively influencing overall team performance and team creativity, respectively. The results are consistent with our theoretical arguments that team effectiveness is not always a product of the average efforts of all the members, but rather a consequence of a few specific members’ idiosyncratic actions, especially when these members occupy central positions in team networks. Below, we discuss some key implications for theory and practice, and point out new directions for future research.

\section{Theoretical Implications}

The findings suggest several important implications for team research. First of all, our study complements the dominant perspective in team research that individuals contribute equally to team overall properties by demonstrating the disproportional influences of specific members on team overall outcomes. Our approach is consistent with a popular principle (i.e., the Pareto 
principle, also known as the 80-20 rule) employed in multiple disciplines such as economics, marketing, and computer science. The principle suggests that for many events, roughly $80 \%$ of the effects come from $20 \%$ of the causes. Similarly, in organizational research, O’Boyle and Aguinis (2012) have empirically demonstrated that individual performance distributions are highly skewed whereby a small portion of outstanding performers contributes the majority of productivity. For example, they found that the top percentile contributes to $10 \%$ of the productivity, and the top 5\% of employees derive $26 \%$ of the output. Therefore, it becomes critically important to pay attention to the influence of key members in teams. As indicated by our findings, as little as one member could profoundly influence team overall processes and effectiveness, particularly when the member is well connected in the team workflow network. Importantly, we demonstrated that the joint influence of the extra miler's behavior and network position explained much more variance in team processes than the other members' aggregated behavior did. Therefore, the results of our research suggest a more complete paradigm of teams research; in addition to examining the average influence of team members, researchers need consider the disproportional influence of the vital few actors in teams.

Second, continuing the effort of integrating two disconnected research streams (i.e., team research and social network research), we proposed a structural network contingency (i.e. network centrality) that is largely overlooked in the current operationalization of team properties. The traditional approach to operationalize team properties based on maximum or minimum scores rarely considers the personal profiles of the members occupying those maximum or minimum scores. The meta-analysis of different operationalization of team composition variables on team effectiveness found inconsistent effects of maximum and minimum scores on team effectiveness (Bell, 2007). The significant interaction between the extra miler's behaviors 
and workflow network centrality found in our study shed a light on the mixed meta-analytic findings. Our result of $7 \%$ incremental variance contributed by the interaction indicates that the extra miler's network position in the team greatly alters his/her contribution to the overall team effectiveness. In other words, for a team where other team members are less dependent on the extra miler (i.e. the most frequent helping member) in terms of work related tasks, the influence of the maximum helping member on overall team outcomes is less profound.

Third, building upon minority influence theory (Grant \& Patil, 2012), we empirically supported two key paths (e.g., helping and voice) whereby an extra miler influences team overall processes and effectiveness. In addition to testing key ideas proposed in their theory, we extended the original model in several important ways. Drawing on social network theory, we theorized and tested the important role of the extra miler's workflow centrality in amplifying team members' behavioral influences on team outcomes. Our findings that the extra miler's contribution is above and beyond the rest of the team demonstrate the importance of behavioral consistency in the minority influence process. Last but not the least, we extended the original model by empirically testing not only the positive effects on team processes but also on performance consequences of the extra milers’ influences. Specifically, we included two key aspects of team effectiveness, team performance and team creativity, as unique consequences of extra milers’ helping and voice actions.

Finally, previous research has suggested that helping and voice represent discrete natures of extra-role behavior (i.e., affiliative versus challenge-oriented) and hence tend to result in unique consequences (McAllister, Kamdar, Morrison, \& Turban, 2007; Van Dyne, Kamdar, \& Joireman, 2008). For example, helping behavior facilitates group cohesion and hence may suppress dissent expressions that challenge the status quo. However, some other studies argue 
that both helping and voice are functional actions, which tend to have positive influences on different aspects of team effectiveness. In other words, helping may have a spillover effect on team creativity and voice may influence team performance. Based on our supplementary analyses, the maximum helping member in a central position had an indirect effect on team creativity performance via team monitoring and backup process, but the voice member had no spillover effect on team performance. This finding is also consistent with Grant and Patil's speculation that "when members are willing to engage in helping, they are more likely to offer new perspectives that facilitate problem-solving and creativity” (2012, p. 561). However, it is unclear why voice behavior had limited impact on team effectiveness. This may be related to our specific research setting such that in the Chinese society, behaviors that challenge the status quo may not be well received (Liang, Farh, \& Farh, 2012).

\section{Managerial Implications}

We suggest several actions that managers can take to increase team effectiveness. First, and most importantly, managers should be aware of the disproportional contributions of team members to team performance. As suggested by our study, a central member's helping and voice behaviors have much stronger effects on team processes and ultimately team effectiveness than a peripheral member's behaviors and possibly the rest team members' behaviors. This is consistent with similar findings in other related areas such as economics, marketing, and performance management that a minority of inputs contributes to a majority of outcomes (Koch, 1999;

O’Boyle \& Aguinis, 2012). We therefore suggest team leaders pay special attention to these vital few and assist them in positively influencing team performance.

Second and related, to fully capitalize on the extra miler's behavioral influences, managers should take actions to enhance the member's position in the team and make sure the 
member has frequent opportunities to interact with others. For example, some teams may not be able to take advantage of members' frequent extra-role actions because these members are isolated in the teams. Previous research has suggested that leaders can leverage their followers’ influences by developing high quality relationships with them (Sparrowe \& Liden, 2005). As a result, managers can proactively increase the extra miler's opportunities to interact with others and centrality in the teams.

Finally, as numerous studies have suggested, team processes play a vital role in driving team performance (LePine, Piccolo, Jackson, Mathieu, \& Saul, 2008) and team leaders are expected to optimize team processes. Our research suggests a new way to enhance team collaboration and interactions. In line with Grant and Patil’s (2012) work on minority influence, team leaders can work with key minority members to positively influence team overall dynamics. For example, managers may consider providing feedback, support, and positive reinforcement to encourage a few members’ challenging behaviors.

\section{Limitation and Future Research}

Although most of our hypotheses were supported, certain limitations should be addressed in future research. First, we conducted our study in China, which may limit the generalizability of our findings. However, recent research across different disciplines and areas has suggested highly consistent findings across different societies (e.g., Chen, Tjosvold, \& Liu, 2006; Kirkman, Chen, Farh, Chen, \& Lowe, 2009), which alleviates some of this concern. It is still important to note the potential influences of the research setting on our results. Specifically, Chinese society has been described as high collectivism (i.e., beliefs emphasizing the priority of group goals over individual goals; Hofstede, 1980). As a result, the influence of minority members on team dynamics could be constrained by high collectivism orientation because employees may feel 
uncomfortable challenging team established processes and norms. Therefore, our hypothesis tests could be considered as conservative. Importantly, our research is based on a general theoretical framework (Grant \& Patil, 2012) with many assumptions based on Western organizational studies, but tested in a specific setting. Therefore, our approach helps validate the theory in a broad scope.

Second, as we used a cross-sectional design, we cannot draw definitive conclusions about causality. Longitudinal research is therefore necessary, and causality can also be strengthened by experimental or quasi-experimental work (Grant \& Wall, 2009). For example, future researchers can employ a longitudinal research design to underpin the reciprocal relationships between the extra miler's influence on team processes and the effect of team dynamics on the extra miler's status in the team.

Third, our study takes an actor focused perspective by examining the extra miler's behavior and network position. However, as Grant and Patil (2012) proposed, characteristics of other members of the work unit (e.g., agreeableness and openness) may also affect the minority influencing process. Therefore, future research could consider the role of other members in shaping team processes and team effectiveness. For example, the relationship between the extra miler and other teammates may be a key factor determining the degree to which the team accepts the extra miler's behavioral influence.

Fourth, one strength of our research is to consider both the frequency of specific behaviors and the source of the behavior (e.g., whether a behavior is performed by a central or peripheral member). As mentioned previously, a team member can exhibit positive or negative influences on team outcomes. In the present study, drawing on Grant and Patil's theory of minority influence, we exclusively focused on two functional behaviors, helping and voice, as an 
initial step to incorporating a social network perspective into team research. Our approach can be extended to examining the joint effect of a member's network position and the member's detrimental impact (e.g., bad apple influence, Kish-Gephart, Harrison, \& Trevino, 2010) on team dynamics and effectiveness. A number of studies have indicated that shirking, social loafing and free-riding could significantly reduce team members’ motivation and team effectiveness (Kidwell \& Bennett, 1993), particularly in highly interdependent teams where individuals’ contributions cannot be easily recognized (Kahai, Sosik, \& Avolio, 2003; Liden, Wayne, Jaworski, \& Bennett, 2004). It would be interesting to examine how a member’s free-riding behavior influences team coordination and how the behavior spreads through the team via social ties among members.

For example, previous research has examined how social loafing behaviors (i.e., intentionally withholding effort) reduce team performance (Albanese \& van Fleet, 1985; Kameda, Tsukasaki, Hastie, \& Berg, 2011; Karau \& Williams, 1993). Building on our framework, scholars may further investigate the interactive effect of a member's social loafing behavior and the member's position on team outcomes. Specifically, if a member intensively interacts with others in a team, the member's social loafing actions are particularly detrimental to the team. This is because other members who frequently interact with the "shirker" tend to reduce their efforts to maintain a balanced reciprocity in team interactions (Emerson, 1976; Mitchell, Cropanzano, \& Quisenberry, 2012). In contrast, a member who does not often interact with others tends to have limited impact on others even if he or she engages in social loafing behavior.

\section{Conclusion}

Both conventional wisdom and theoretical reasoning has suggested the disproportional influences of a few key inputs, causes, and individuals on a system’s overall outputs, 
performance, and effectiveness. However, team research has not fully embraced this key idea. Therefore, drawing on minority influence theory, our research examines the critical role of the extra miler in influencing team overall dynamics and outcomes. We hope that our study will catalyze future research to further explore the complex interplay between the "parts" and the "whole" of the team, and eventually generate a better understanding of team effectiveness. 


\section{References}

Albanese, R., \& Van Fleet, D. D. (1985). Rational behavior in groups: The free-riding tendency. Academy of Management Review, 10, 244-255.

Amabile, T., \& Gryskiewicz, S. S. (1987). Creativity in the R\&D laboratory. Greensboro, NC: Center for Creative Leadership.

Anderson, S. E., \& Williams, L. J. (1996). Interpersonal, job, and individual factors related to helping processes at work. Journal of Applied Psychology, 81, 282-296.

Bain, P. G., Mann, L., \& Pirola-Merlo, A. (2001). The innovation imperative: The relationships between team climate, innovation, and performance in research and development teams. Small Group Research, 32, 55-73.

Balkundi, P., \& Harrison, D. A. (2006). Ties, leaders, and time in teams: Strong inference about network structure's effects on team viability and performance. Academy of Management Journal, 49, 49-68.

Bandura, A. (1977). Social learning theory. Englewood Cliffs, NJ: Prentice-Hall

Baron, R. M., \& Kenny, D. A. (1986). The moderator-mediator variable distinction in social psychological research: Conceptual, strategic, and statistical considerations. Journal of Personality and Social Psychology, 51, 1173-1182.

Barrick, M. R., Stewart, G. L., Neubert, M. J., \& Mount, M. K. (1998). Relating member ability and personality to work-team processes and team effectiveness. Journal of Applied Psychology, 83, 377-391.

Bell, S. T. (2007). Deep-level composition variables as predictors of team performance: A metaanalysis. Journal of Applied Psychology, 92, 595-615.

Bettenhausen, K., \& Murnighan, J. K. (1985). The emergence of norms in competitive decision- 
making groups. Administrative Science Quarterly, 30, 350-372.

Bliese, P. D. (1998). Group size, ICC values, and group-level correlations: A simulation. Organizational Research Methods, 1, 355-373.

Bliese, P. D. (2000). Within-group agreement, non-independence, and reliability: Implications for data aggregation and analysis. In K. J. Klein \& S. W. J. Kozlowski (Eds.), Multilevel theory, research, and methods in organizations: Foundations, extensions, and new directions (pp. 349-381). San Francisco, CA: Jossey-Bass.

Borgatti, S. P., Everett, M. G., \& Freeman, L. C. (2002). Ucinet for Windows: Software for social network analysis. Harvard, MA: Analytic Technologies.

Borgatti, S. P., Mehra, A., Brass, D. J., \& Labianca, G. (2009). Network analysis in the social sciences. Science, 323, 892-895.

Brass, D. J. (1984). Being in the right place: A structural analysis of individual influence in an organization. Administrative Science Quarterly, 29, 518-539.

Brass, D. J., Galaskiewicz, J., Greve, H. R., \& Tsai, W. (2004). Taking stock of networks and organizations: A multilevel perspective. Academy of Management Journal, 47, 795-817.

Brown, M. E., \& Trevino, L. K. (2006). Socialized charismatic leadership, values congruence, and deviance in work groups. Journal of Applied Psychology, 91, 954.

Brief, A. P., \& Motowidlo, S. J. (1986). Prosocial organizational behaviors. Academy of Management Review, 11, 710-725.

Brislin, R. W. (1986). The wording and translation of research instruments. In W. J. Lonner \& J. W. Berry (Eds.), Field methods in cross-cultural research (Vol. 8, pp. 137-164). Thousand Oaks, CA: Sage Publications, Inc.

Campion, M. A., Medsker, G. J., \& Higgs, A. C. (1993). Relations between work group 
characteristics and effectiveness: Implications for designing effective work groups. Personnel Psychology, 46, 823-847.

Chen, G., Tjosvold, D., \& Liu, C. (2006). Cooperative goals, leader people and productivity values: Their contribution to top management teams in China. Journal of Management Studies, 43, 1177-1200.

Chiaburu, D. S., Oh, I.-S., Berry, C. M., Li, N., \& Gardner, R. G. (2011). The five-factor model of personality traits and organizational citizenship behaviors: A meta-analysis. Journal of Applied Psychology, 96, 1140-1166.

Cialdini, R. B., \& Goldstein, N. J. (2004). Social influence: Compliance and conformity. Annual Review of Psychology, 55, 591-621.

Dickinson, T. L., \& McIntyre, R. M. (1997). A conceptual framework for teamwork measurement. In M. T. Brannick, E. Salas \& C. Prince (Eds.), Team performance and measurement: Theory, methods, and applications (pp. 19-43). Mahwah, NJ: Lawrence Erlbaum Associates.

Drazin, R., Glynn, M. A., \& Kazanjian, R. K. (1999). Multilevel theorizing about creativity in organizations: A sensemaking perspective. Academy of Management Review, 24, 286307.

Dukerich, J. M., Golden, B. R., \& Shortell, S. M. (2002). Beauty is in the eye of the beholder: The impact of organizational identification, identity, and image on the cooperative behaviors of physicians. Administrative Science Quarterly, 47, 507-533.

Dutton, J. E., Worline, M. C., Frost, P. J., \& Lilius, J. (2006). Explaining compassion organizing. Administrative Science Quarterly, 51, 59-96.

Edwards, J. R., \& Lambert, L. S. (2007). Methods for integrating moderation and mediation: A 
general analytical framework using moderated path analysis. Psychological Methods, 12, 1-22.

Emerson, R. M. (1976). Social exchange theory. Annual Review of Sociology, 2, 335-362.

Farh, J. L., Hackett, R. D., \& Liang, J. (2007). Individual-level cultural values as moderators of perceived organizational support-employee outcome relationships in China: Comparing the effects of power distance and traditionality. Academy of Management Journal, 50, 715-729.

Farh, J. L., Zhong, C. B., \& Organ, D. W. (2004). Organizational citizenship behavior in the People's Republic of China. Organization Science, 15, 241-253.

George, J. M., \& Bettenhausen, K. (1990). Understanding prosocial behavior, sales performance, and turnover: A group-level analysis in a service context. Journal of Applied Psychology, 75, 698-709.

George, J. M., \& Brief, A. P. (1992). Feeling good-doing good: a conceptual analysis of the mood at work-organizational spontaneity relationship. Psychological Bulletin, 112, 310329.

Grant, A. M., \& Patil, S. V. (2012). Challenging the norm of self-interest: Minority influence and transitions to helping norms in work units. Academy of Management Review, 37, 547568.

Grant, A. M., \& Wall, T. D. (2009). The neglected science and art of quasi-experimentation why-to, when-to, and how-to advice for organizational researchers. Organizational Research Methods, 12, 653-686.

Hayes, A. F. (2009). Beyond Baron and Kenny: Statistical mediation analysis in the new millennium. Communication Monographs, 76, 408-420. 
Hayes, A.F. (2013). An introduction to mediation, moderation, and conditional process analysis: A regression-based approach. New York: Guilford Press.

Hofmann, D. A., \& Jones, L. M. (2005). Leadership, collective personality, and performance. Journal of Applied psychology, 90, 509-522.

Hofstede, G. (1980). Culture's consequences: International differences in work-related values (Vol. 5). Sage Publications, Incorporated.

Humphrey, S. E., Morgeson, F. P., \& Mannor, M. J. (2009). Developing a theory of the strategic core of teams: A role composition model of team performance. Journal of Applied Psychology, 94, 48-61.

Ilies, R., Wagner, D. T., \& Morgeson, F. P. (2007). Explaining affective linkages in teams: individual differences in susceptibility to contagion and individualism-collectivism. Journal of Applied Psychology, 92, 1140-1148.

Jöreskog, K. G., \& Sörbom, D. (1993). LISREL 8: Structural equation modeling with the SIMPLIS command language: Scientific Software.

Kahai, S. S., Sosik, J. J., \& Avolio, B. J. (2003). Effects of leadership style, anonymity, and rewards on creativity-relevant processes and outcomes in an electronic meeting system context. The Leadership Quarterly, 14, 499-524.

Kahn, W. A. (1998). Relational systems at work. Research in Organizational Behavior, 20, 3976.

Kameda, T., Tsukasaki, T., Hastie, R., \& Berg, N. (2011). Democracy under uncertainty: The wisdom of crowds and the free-rider problem in group decision making. Psychological review, 118, 76-96.

Karau, S. J., \& Williams, K. D. (1993). Social loafing: A meta-analytic review and theoretical 
integration. Journal of Personality and Social Psychology, 65, 681-706.

Kay, P. (1989). An act frequency study of exit, voice, loyalty and neglect. Unpublished honors thesis. Department of Psychology. Queen's University, Kingston. Ontario.

Kidwell, R. E., \& Bennett, N. (1993). Employee propensity to withhold effort: A conceptual model to intersect three avenues of research. Academy of Management Review, 18, 429456.

Kilduff, M., \& Brass, D. J. (2010). Organizational social network research: Core ideas and key debates. The Academy of Management Annals, 4, 317-357.

Kirkman, B. L., Chen, G., Farh, J.L., Chen, Z. X., \& Lowe, K. B. (2009). Individual power distance orientation and follower reactions to transformational leaders: A cross-level, cross-cultural examination. Academy of Management Journal, 52, 744-764.

Kish-Gephart, J. J., Harrison, D. A., \& Treviño, L. K. (2010). Bad apples, bad cases, and bad barrels: meta-analytic evidence about sources of unethical decisions at work. Journal of Applied Psychology, 95, 1-31.

Klein, K. J., Saltz, J. L., \& Mayer, D. M. (2004). How do they get there? An examination of the antecedents of centrality in team networks. Academy of Management Journal, 47, 952963.

Koch, R. (1999). The 80/20 principle: The secret of achieving more with less. Garden City, NY: Doubleday and Company, Inc.

Kozlowski, S. W. J., \& Klein, K. J. (2000). A multilevel approach to theory and research in organizations: contextual, temporal, and emergent processes. In K. J. Klein \& S. W. J. Kozlowski (Eds.), Multilevel theory, research, and methods in organizations: Foundations, extensions and new directions (pp. 3-90). San Francisco, CA: Jossey-Bass. 
Kukenberger, M. R., Mathieu, J. E., \& Ruddy, T. (2012). A Cross-Level Test of Empowerment and Process Influences on Members’ Informal Learning and Team Commitment. Journal of Management.

LePine, J. A., Hollenbeck, J. R., Ilgen, D. R., \& Hedlund, J. (1997). Effects of individual differences on the performance of hierarchical decision-making teams: Much more than g. Journal of Applied Psychology, 82, 803-811.

LePine, J. A., Piccolo, R. F., Jackson, C. L., Mathieu, J. E., \& Saul, J. R. (2008). A meta-analysis of teamwork processes: tests of a multidimensional model and relationships with team effectiveness criteria. Personnel Psychology, 61, 273-307.

LePine, J. A., \& Van Dyne, L. (1998). Predicting voice behavior in work groups. Journal of Applied Psychology, 83, 853-868.

LePine, J. A., \& Van Dyne, L. (2001). Voice and cooperative behavior as contrasting forms of contextual performance: Evidence of differential relationships with Big Five personality characteristics and cognitive ability. Journal of Applied Psychology, 86, 326-336.

Li, N., Kirkman, B., \& Porter, C. (2014). Toward a model of work team altruism. Academy of Management Review.

Liang, J., Farh, C. I., \& Farh, J. L. (2012). Psychological antecedents of promotive and prohibitive voice: A two-wave examination. Academy of Management Journal, 55, 7192.

Liden, R. C., Wayne, S. J., Jaworski, R. A., \& Bennett, N. (2004). Social loafing: A field investigation. Journal of Management, 30, 285-304.

Madjar, N., Greenberg, E., \& Chen, Z. (2011). Factors for radical creativity, incremental creativity, and routine, noncreative performance. Journal of Applied Psychology, 96, 730- 
743.

Marks, M. A., Mathieu, J. E., \& Zaccaro, S. J. (2001). A temporally based framework and taxonomy of team processes. Academy of Management Review, 26, 356-376.

Marks, M. A., \& Panzer, F. J. (2004). The influence of team monitoring on team processes and performance. Human Performance, 17, 25-41.

Marsden, P. V., \& Friedkin, N. E. (1993). Network studies of social influence. Sociological Methods \& Research, 22, 127-151.

Mathieu, J., \& Marks, M. (2006). Team process items. Unpublished manuscript.

Mathieu, J., Maynard, M. T., Rapp, T., \& Gilson, L. (2008). Team effectiveness 1997-2007: A review of recent advancements and a glimpse into the future. Journal of Management, 34, 410-476.

Mathieu, J. E., Heffner, T. S., Goodwin, G. F., Salas, E., \& Cannon-Bowers, J. A. (2000). The influence of shared mental models on team process and performance. Journal of Applied Psychology, 85, 273-283.

McAllister, D. J., Kamdar, D., Morrison, E. W., \& Turban, D. B. (2007). Disentangling role perceptions: How perceived role breadth, discretion, instrumentality, and efficacy relate to helping and taking charge. Journal of Applied Psychology, 92, 1200-1211.

McClean, E., Burris, E., \& Detert, J. (2013). When does voice lead to exit? It depends on leadership. Academy of Management Journal, 56, 525-548.

Mitchell, M. S., Cropanzano, R. S., \& Quisenberry, D. M. (2012). Social exchange theory, exchange resources, and interpersonal relationships: A modest resolution of theoretical difficulties. In Handbook of social resource theory (pp. 99-118). New York, NY: Springer. 
Neuman, G. A., \& Wright, J. (1999). Team effectiveness: beyond skills and cognitive ability. Journal of Applied Psychology, 84, 376-389.

O’Boyle Jr, E., \& Aguinis, H. (2012). The best and the rest: Revisiting the norm of normality of individual performance. Personnel Psychology, 65, 79-119.

Organ, D. W. (1988). Organizational citizenship behavior: The good soldier syndrome (Vol. 133): Lexington books Lexington, MA.

Ouchi William, G. (1979). A Conceptual Framework for the Design of Organizational Control Mechanism. Management Science, 25, 833-848.

Porter, C. O. L. H., Hollenbeck, J. R., Ilgen, D. R., Ellis, A. P. J., West, B. J., \& Moon, H. (2003). Backing up behaviors in teams: The role of personality and legitimacy of need. Journal of Applied Psychology, 88, 391-403.

Preacher, K. J., \& Hayes, A. F. (2008). Asymptotic and resampling strategies for assessing and comparing indirect effects in multiple mediator models. Behavior Research Methods, 40, 879-891.

Scott, B. A., \& Judge, T. A. (2009). The popularity contest at work: who wins, why, and what do they receive? Journal of Applied Psychology, 94, 20-33.

Schultz, P. W., Nolan, J. M., Cialdini, R. B., Goldstein, N. J., \& Griskevicius, V. (2007). The constructive, destructive, and reconstructive power of social norms. Psychological Science, 18, 429-434.

Sparrowe, R. T., \& Liden, R. C. (2005). Two routes to influence: Integrating leader-member exchange and social network perspectives. Administrative Science Quarterly, 50, 505535.

Sparrowe, R. T., Liden, R. C., Wayne, S. J., \& Kraimer, M. L. (2001). Social networks and the 
performance of individuals and groups. Academy of Management Journal, 44, 316-325.

Tangirala, S., \& Ramanujam, R. (2008). Employee silence on critical work issues: The cross level effects of procedural justice climate. Personnel Psychology, 61, 37-68.

Van de Ven, A. H., \& Johnson, P. E. (2006). Knowledge for theory and practice. Academy of Management Review, 31, 802-821.

Van Der Vegt, G. S., Bunderson, J. S., \& Oosterhof, A. (2006). Expertness diversity and interpersonal helping in teams: Why those who need the most help end up getting the least. Academy of Management Journal, 49, 877-893.

Van Dyne, L., Cummings, L. L., \& Parks, J. M. (1995). Extra-role behaviors: In pursuit of construct and definitional clarity (a bridge over muddied waters). Research in Organizational Behavior, 17, 215-215.

Van Dyne, L., Kamdar, D. A., \& Joireman, J. (2008). In-role perceptions buffer the negative impact of low LMX on helping and enhance positive impact of LMX on voice. Journal of Applied Psychology, 93, 1195-1207.

Van Dyne, L., \& LePine, J. A. (1998). Helping and voice extra-role behaviors: Evidence of construct and predictive validity. Academy of Management Journal, 41, 108-119.

Venkataramani, V., \& Tangirala, S. (2010). When and why do central employees speak up? An examination of mediating and moderating variables. Journal of Applied Psychology, 95, 582-559.

Weick, K. E., \& Sutcliffe, K. M. (2001). Managing the unexpected: Assuring high performance in an age of complexity. San Francisco: Jossey-Bass.

West, M. A., \& Anderson, N. R. (1996). Innovation in top management teams. Journal of Applied psychology, 81, 680-693. 
Wood, W., Lundgren, S., Ouellette, J. A., Busceme, S., \& Blackstone, T. (1994). Minority influence: a meta-analytic review of social influence processes. Psychological Bulletin, 115, 323-325.

Woodman, R. W., Sawyer, J. E., \& Griffin, R. W. (1993). Toward a theory of organizational creativity. Academy of Management Review, 18, 293-321.

Zhang, Z. X., Hempel, P. S., Han, Y. L., \& Tjosvold, D. (2007). Transactive memory system links work team characteristics and performance. Journal of Applied Psychology, 92, 1722-1730.

Zhou, J., \& George, J. M. (2001). When job dissatisfaction leads to creativity: Encouraging the expression of voice. Academy of Management Journal, 44, 682-696.

Zohar, D., \& Tenne-Gazit, O. (2008). Transformational leadership and group interaction as climate antecedents: a social network analysis. Journal of Applied Psychology, 93, 744757. 


\section{Table 1}

Correlation Matrix and Descriptive Statistics

\begin{tabular}{|c|c|c|c|c|c|c|c|c|c|}
\hline & $M$ & $S D$ & 1 & 2 & 3 & 4 & 5 & 6 & 7 \\
\hline 1. Team Size & 7.61 & 4.47 & & & & & & & \\
\hline 2. Workflow Centralization & 0.19 & 0.11 & $-.29 *$ & & & & & & \\
\hline 3. Workflow Density & 3.42 & 0.63 & $-.42 *$ & -.04 & & & & & \\
\hline 4. Team Performance & 5.16 & 0.87 & .11 & -.12 & .14 & & & & \\
\hline 5. Team Creativity & 5.35 & 0.88 & .12 & -.08 & .08 & $.52 *$ & & & \\
\hline 6. Monitoring Backup Process & 5.72 & 0.50 & -.11 & .17 & $.25 *$ & $.28 *$ & .18 & & \\
\hline 8. Helping Dispersion & 0.39 & 0.24 & -.05 & $.34^{*}$ & $-.42 *$ & $-.24^{*}$ & $-.34 *$ & -.11 & -.12 \\
\hline 9. Helping team partial mean & 5.32 & 0.74 & -.14 & -.11 & $.73 *$ & $.21 *$ & .12 & $.37 *$ & $.82 *$ \\
\hline 10. Workflow Centrality Helping & 76.04 & 14.30 & $-.33 *$ & .11 & $.66^{*}$ & .03 & -.15 & .10 & $.41^{*}$ \\
\hline 11. Voice (Max) & 5.81 & 0.65 & -.09 & .16 & $.56^{*}$ & .17 & .06 & $.44^{*}$ & $.80 *$ \\
\hline 12. Voice Dispersion & 0.36 & 0.20 & -.07 & $.43 *$ & $-.32 *$ & -.18 & $-.33 *$ & $-.23 *$ & -.14 \\
\hline 13. Voice team partial mean & 5.21 & 0.75 & -.11 & -.06 & $.67 *$ & $.24 *$ & .18 & $.49 *$ & $.74 *$ \\
\hline 14. Workflow Centrality Voice & 77.71 & 13.84 & $-.44 *$ & .12 & $.67 *$ & .01 & -.14 & .05 & $.36 *$ \\
\hline
\end{tabular}

Note. Workflow Centrality Helping = Workflow centrality of the team member with the highest helping rating; Workflow Centrality Voice = Workflow centrality of the team member with the highest voice rating

$\mathrm{N}=87 .{ }^{*} \mathrm{p}<.05$ 
Table 1 (Cont.).

Correlation Matrix and Descriptive Statistics

\begin{tabular}{|c|c|c|c|c|c|c|c|c|}
\hline & $M$ & $S D$ & 8 & 9 & 10 & 11 & 12 & 13 \\
\hline 1. Team Size & 7.61 & 4.47 & & & & & & \\
\hline 2. Workflow Centralization & 0.19 & 0.11 & & & & & & \\
\hline 3. Workflow Density & 3.42 & 0.63 & & & & & & \\
\hline 4. Team Performance & 5.16 & 0.87 & & & & & & \\
\hline 5. Team Creativity & 5.35 & 0.88 & & & & & & \\
\hline 6. Monitoring Backup Process & 5.72 & 0.50 & & & & & & \\
\hline 7. Helping (Max) & 5.93 & 0.61 & & & & & & \\
\hline 8. Helping Dispersion & 0.39 & 0.24 & & & & & & \\
\hline 9. Helping team partial mean & 5.32 & 0.74 & $-.58 *$ & & & & & \\
\hline 10. Workflow Centrality Helping & 76.04 & 14.30 & -.18 & $.42 *$ & & & & \\
\hline 11. Voice (Max) & 5.81 & 0.65 & $-.25 *$ & $.76^{*}$ & $.43^{*}$ & & & \\
\hline 12. Voice Dispersion & 0.36 & 0.20 & $.60 *$ & $-.46^{*}$ & .05 & -.09 & & \\
\hline 13. Voice team partial mean & 5.21 & 0.75 & $-.46^{*}$ & $.88 *$ & $.35 *$ & $.88 *$ & $-.50 *$ & \\
\hline 14. Workflow Centrality Voice & 77.71 & 13.84 & $-.24 *$ & $.42^{*}$ & $.87^{*}$ & $.37 *$ & .04 & $.30 *$ \\
\hline
\end{tabular}

Note. Workflow Centrality Helping = Workflow centrality of the team member with the highest helping rating; Workflow Centrality Voice $=$ Workflow centrality of the team member with the highest voice rating

$\mathrm{N}=87 .{ }^{*} \mathrm{p}<.05$ 


\section{Table 2}

Results of Confirmatory Factor Analyses

\begin{tabular}{|c|c|c|c|c|c|c|c|}
\hline Model & Descriptions & $\chi^{2}$ & $\mathrm{df}$ & $\Delta \chi^{2}$ & CFI & RMSEA & SRMR \\
\hline Baseline & $\begin{array}{l}\text { Five factors: voice, helping, monitoring and } \\
\text { backup, performance, team creativity }\end{array}$ & 66.68 & 55 & & .99 & .05 & .05 \\
\hline Model 1 & $\begin{array}{l}\text { Four factors: contextual behaviors, monitoring and } \\
\text { backup, performance, team creativity }\end{array}$ & 86.50 & 59 & $19.82 *$ & .97 & .07 & .05 \\
\hline Model 2 & $\begin{array}{l}\text { Four factors: voice, helping, monitoring and } \\
\text { backup, overall performance }\end{array}$ & 202.87 & 59 & 136.19* & .86 & .17 & .09 \\
\hline Model 3 & $\begin{array}{l}\text { Three factors: contextual behaviors, monitoring } \\
\text { backup, overall performance }\end{array}$ & 222.42 & 62 & $155.74^{*}$ & .84 & .17 & .10 \\
\hline
\end{tabular}

$* p<.01$ 
Table 3

Regression Results Predicting Team Monitoring and Backup From Max Helping member

\begin{tabular}{lcccc}
\hline Variable & Model 1 & Model 2 & Model 3 & Model 4 \\
\cline { 2 - 3 } Constant & $5.76^{*}$ & $5.75^{*}$ & $5.69 *$ & $5.70^{*}$ \\
Team Size & -.02 & -.01 & .00 & -.01 \\
Workflow Centralization & .09 & .10 & .11 & .10 \\
Workflow Density & .04 & .01 & .02 & .05 \\
Helping Dispersion & -.06 & .02 & -.01 & -.09 \\
Helping (Max) & $.18^{*}$ & .05 & -.01 & .11 \\
Workflow Centrality & -.12 & -.10 & -.09 & -.11 \\
Team Helping Mean (rest & & .19 & .17 & \\
members) & & & $.22^{*}$ & $.22^{*}$ \\
Helping (Max) X Workflow & & & .27 & .27 \\
Centrality & .19 & .20 & .20 & .20 \\
$\mathrm{R}^{2}$ & .13 & .13 & $3.66^{*}$ & $4.07^{*}$ \\
Adjusted ${ }^{2}$ & $3.14^{*}$ & $2.84^{*}$ & $.07^{\mathrm{a}}$ & $.01^{\mathrm{b}}$ \\
$\mathrm{F}$ & & .01 & $7.70^{*^{\mathrm{a}}}$ & $.85^{\mathrm{b}}$ \\
$\Delta \mathrm{R}^{2}$ & & 1.02 & & \\
$\Delta \mathrm{F}$ & & & & \\
\hline
\end{tabular}

Notes. ${ }^{*} \mathrm{p}<.05 ;{ }^{\text {a }}$ compares M3 with M2, ${ }^{\text {b }}$ compares M3 with M4; Helping (Max) $=$ the member with the highest helping rating, Team Helping Mean (rest members) = the mean score of all the team members except the member with the highest helping rating 
Table 4

Regression Results Predicting Team Monitoring and Backup From Max Voice member

\begin{tabular}{lcccc}
\hline Variable & Model 1 & Model 2 & Model 3 & Model 4 \\
\cline { 2 - 3 } Constant & 5.73 & $5.72^{*}$ & $5.67^{*}$ & $5.68^{*}$ \\
Team Size & -.05 & -.03 & -.02 & -.04 \\
Workflow Centralization & .10 & $.12^{*}$ & $.12^{*}$ & .10 \\
Workflow Density & -.01 & -.05 & -.02 & .01 \\
Voice Dispersion & $-.14^{*}$ & -.02 & -.02 & $-.12^{*}$ \\
Voice (Max) & $.23^{*}$ & -.04 & .01 & $.24^{*}$ \\
Workflow Centrality & -.08 & -.05 & -.06 & -.08 \\
Team Voice Mean (rest & & .32 & .27 & \\
members) & & & $.14^{*}$ & $.14^{*}$ \\
Voice (Max) X Workflow & & & .37 & .36 \\
Centrality & .29 & .31 & .31 & .31 \\
$\mathrm{R}^{2}$ & .24 & .25 & $5.80^{*}$ & $6.41^{*}$ \\
Adjusted $\mathrm{R}^{2}$ & $5.51^{*}$ & $5.01^{*}$ & $.07^{\mathrm{a}}$ & $.01^{\mathrm{b}}$ \\
$\mathrm{F}$ & & .02 & $8.11^{*^{\mathrm{a}}}$ & $1.28^{\mathrm{b}}$ \\
$\Delta \mathrm{R}^{2}$ & & 1.72 & & \\
$\Delta \mathrm{F}$ & & & & \\
\hline
\end{tabular}

Notes. ${ }^{*} \mathrm{p}<.05$; ${ }^{a}$ compares M3 with M2, ${ }^{\mathrm{b}}$ compares M3 with M4; Voice (Max) $=$ the member with the highest voice rating, Team Voice Mean (rest members) = the mean voice score of all the team members except the member with the highest voice rating 


\section{Table 5}

Regression Results for Conditional Indirect Effects Maximum Helping Member on Performance

\begin{tabular}{lcccc}
\hline Predictor & $B$ & $S E$ & $t$ & $p$ \\
\hline Constant & 2.36 & 1.13 & 2.08 & $.04^{*}$ \\
Size & .13 & .11 & 1.12 & .27 \\
Work density & .08 & .15 & .56 & .58 \\
Work centralization & -.06 & .10 & -.53 & .59 \\
Helping dispersion & -.13 & .11 & -1.15 & .25 \\
TMB & .49 & .20 & 2.48 & $.02^{*}$ \\
Helping max member & -.04 & .13 & -.29 & .77 \\
\hline Work centrality & Boot Indirect & Boot SE & Boot LLCI & Boot ULCI \\
& Effect & & \\
$-1 S D$ & Conditional Indirect Effect at Work Centrality $=M \pm 1$ SD & \\
$M$ & .01 & .04 & -.07 & .11 \\
$+1 S D$ & .08 & .04 & .02 & .21 \\
\hline
\end{tabular}

Note. $\mathrm{N}=87$. Bootstrap sample size $=1000$. Level of Confidence Interval $=95 \%$. TMB $=$ Team Monitoring and Backup. Work Centrality $=$ Workflow Centrality 
Table 6

Regression Results for Conditional Indirect Effects Maximum Voice Member on Creativity

\begin{tabular}{lcccc}
\hline Predictor & $B$ & $S E$ & $t$ & $p$ \\
\hline Constant & 4.22 & 1.24 & 3.41 & .00 \\
Size & .12 & .11 & 1.08 & .28 \\
Work density & .03 & .14 & .19 & .85 \\
Work centralization & .08 & .11 & .71 & .48 \\
Helping dispersion & -.29 & .11 & -2.51 & .01 \\
TMB & .20 & .22 & .92 & .36 \\
Helping max member & -.04 & .13 & -.28 & .78 \\
\hline Work centrality & Boot Indirect & Boot SE & Boot LLCI & Boot ULCI \\
& Effect & & \\
$-1 S D$ & Conditional Indirect Effect at Work Centrality $=M \pm 1$ SD & \\
$M$ & .02 & .04 & -.02 & .14 \\
$+1 S D$ & .05 & .06 & -.04 & .19 \\
\hline
\end{tabular}

Note. $\mathrm{N}=87$. Bootstrap sample size $=100$. Level of Confidence Interval = 95\%. $\mathrm{TMB}=\mathrm{Team}$ Monitoring and Backup. Work Centrality = Workflow Centrality 


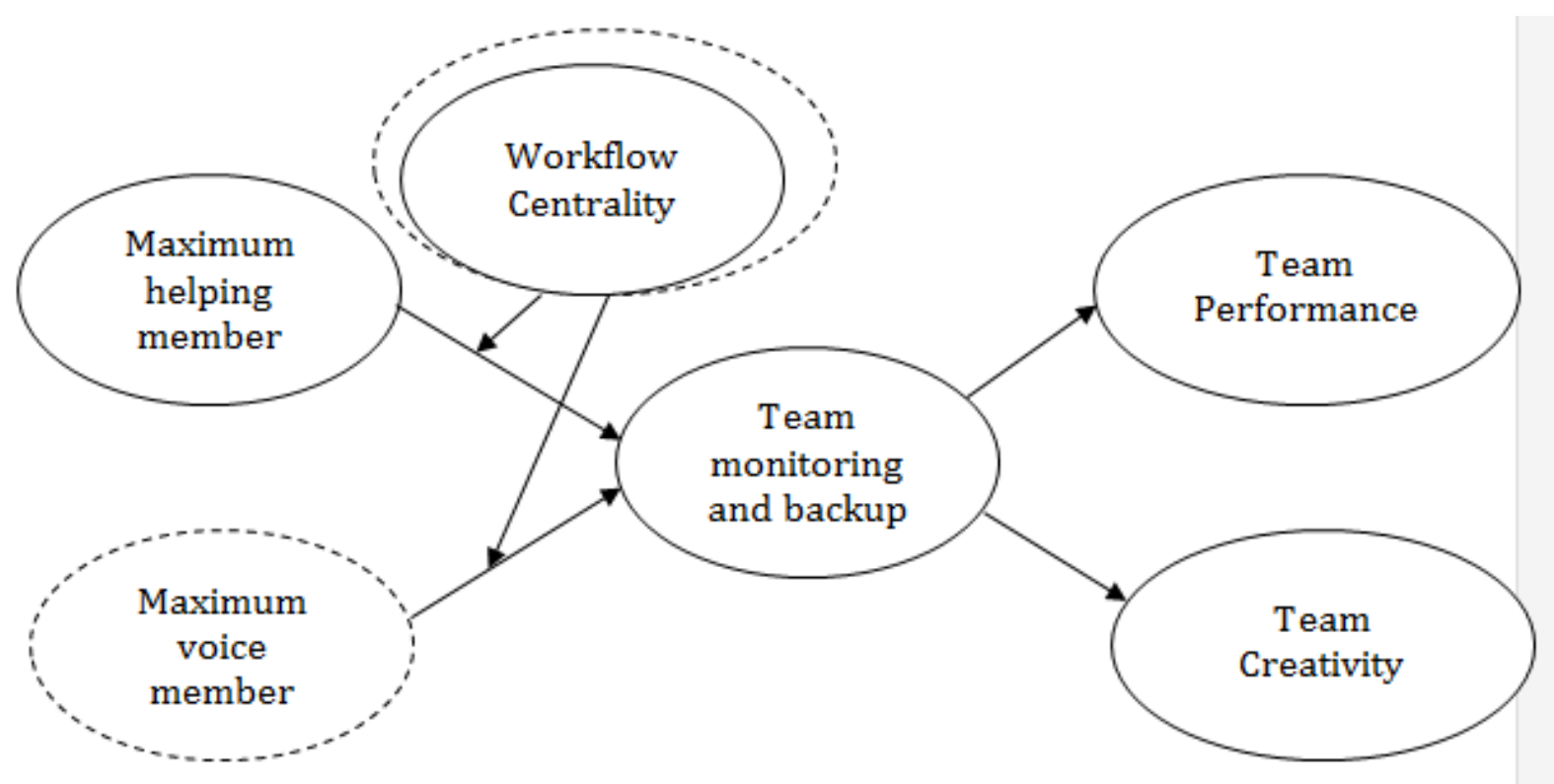

Figure 1. Overall Model

Note: the dashed line indicates that the maximum helping member may not be the same person as the maximum voice member 


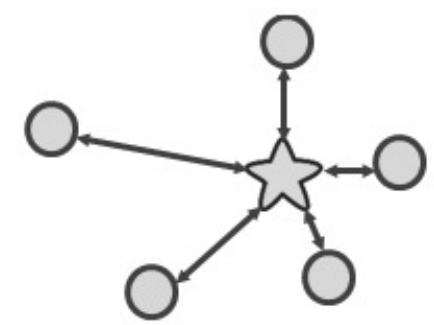

Figure 2a. Extra miler in central network position

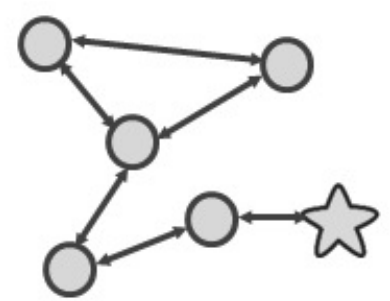

Figure $2 b$. Extra miler in peripheral network position

Figure 2. Graphical Illustration of Extra Miler’s Position in Central and Peripheral Networks 


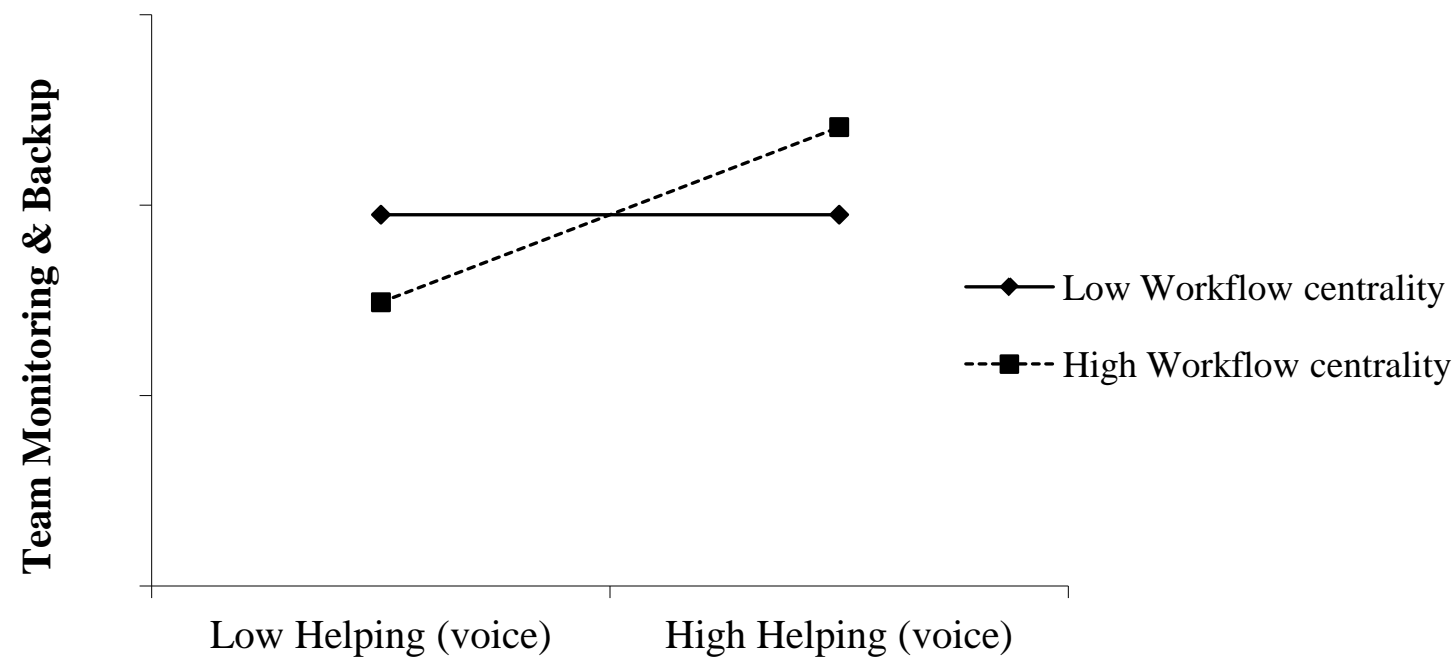

Figure 3. Hypothetical Moderating Effect of Workflow Centrality on the Relationships between Helping (voice) behaviors and Team Monitoring and Backup Process. 


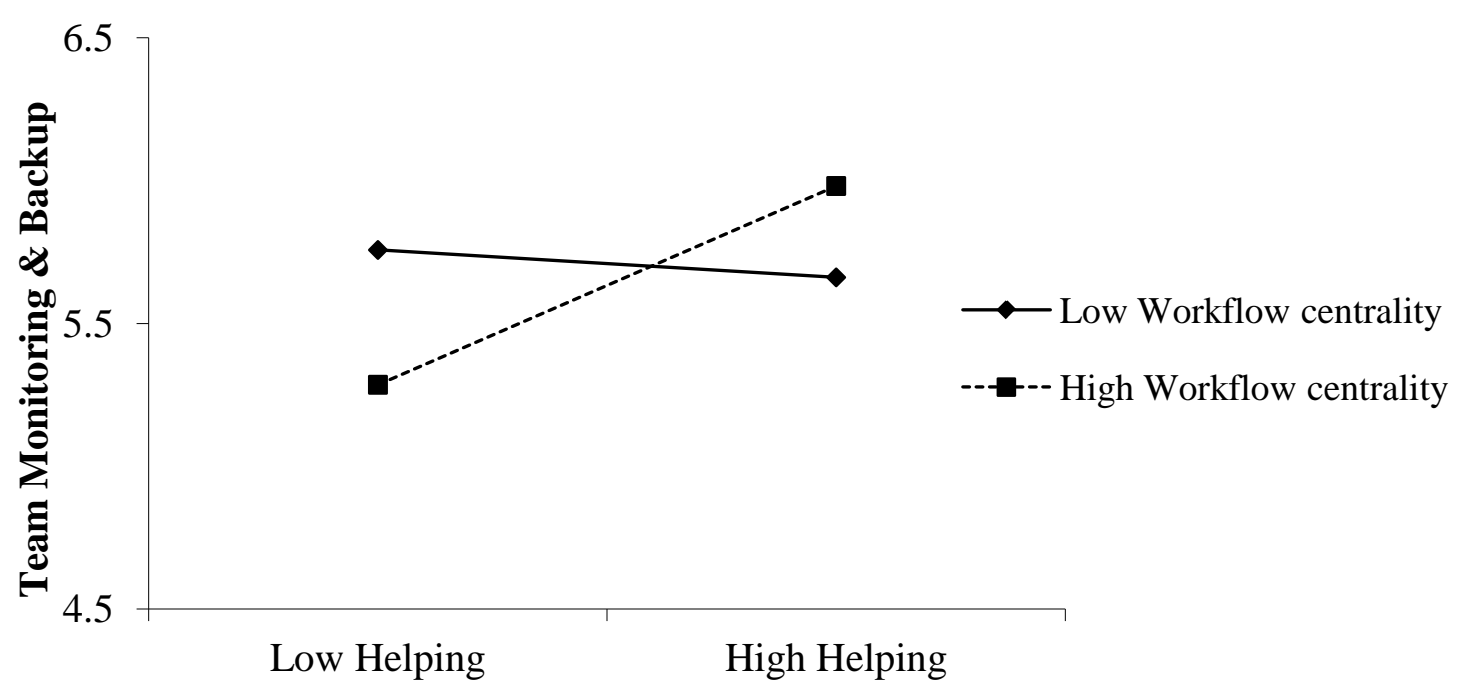

Figure 4a. Moderator Analysis of Workflow Centrality on the Relationship between Helping Behaviors and the Team Monitoring and Backup Process.

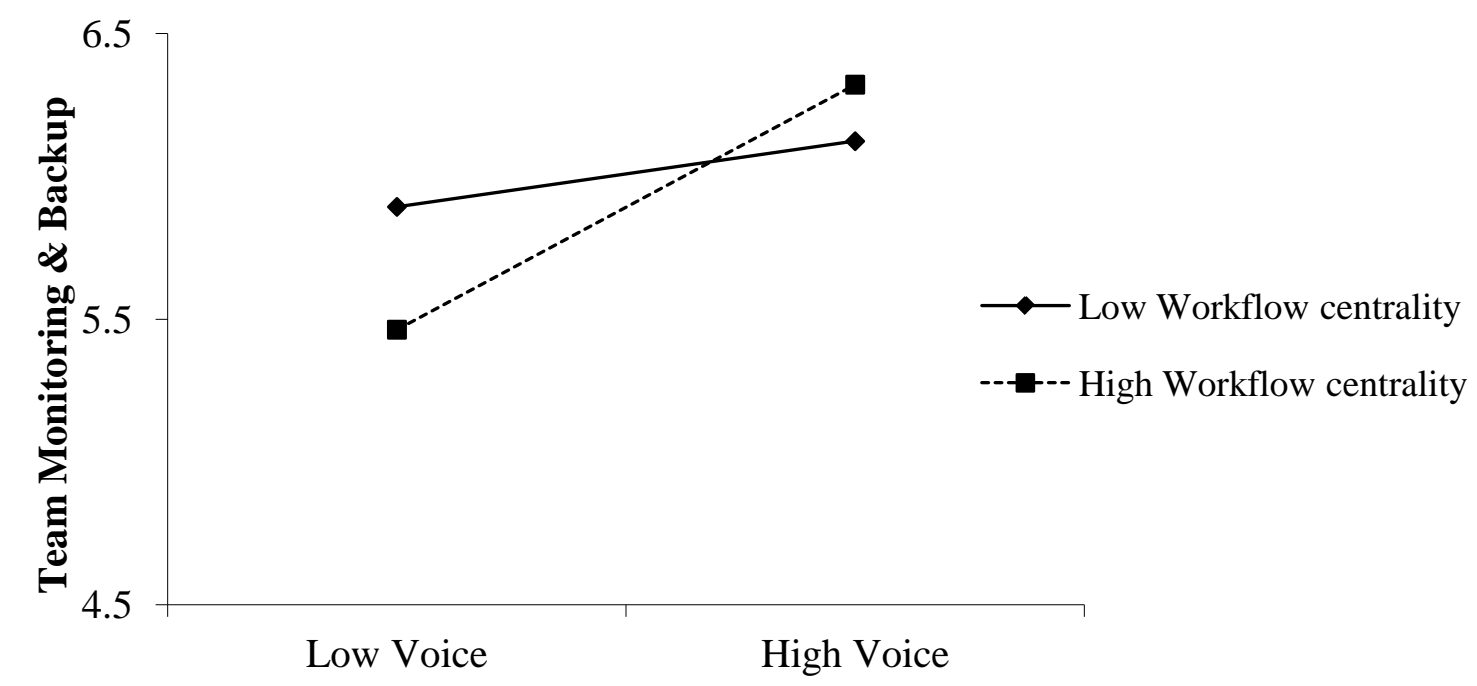

Figure 4b. Moderator Analysis of Workflow Centrality on the Relationship between Voice Behaviors and the Team Monitoring and Backup Process. 